DOI: https://doi.org/10.24867/14FA11Ciconovsk

\author{
ENTERIJERNO UREĐENJE REVITALIZOVANOG OBJEKTA \\ U ULICI SANTE LUSIE 17, MADRID, ŠPANIJA \\ INTERIOR DESIGN OF THE REHABILITATED BUILDING LOCATED \\ ON THE SANTA LUCIA 17 STREET, MADRID, SPAIN
}

\author{
Irena Čičonovska, Fakultet tehničkih nauka, Novi Sad
}

\section{Oblast- ARHITEKTURA}

Kratak sadržaj - U cilju kompletne rehabilitacije objekta urađeno je enterijerno uređenje. Rad sadrži prikaz istraživačkog i projektantskog procesa rada, koji proizilaze jedan iz drugog. Istraživački deo se bavi analizom rehabilitovanih građevina kao i svih parametara vezanih za zadat postojeći objekat i predstavlja osnovnu podlogu projektantske koncepcije. Projektantski deo rada opisuje program i koncept i podrazumeva tehničke crteže $i 3 D$ prikaze.

Abstract - For the purpose of complete rehabilitation of the building, the interior design was done. This thesis contains a review of researching and designing processes which inherit one another.

The researching part of the process deals with analysis of restorated buildings in general as well as all the neccesary parameters needed for the given object, thus it provides the basis for the designing concept.

The designing part defines the program and concept, and also incorporates drawings and $3 D$ representations.

Ključne reči: uređenje enteirjera, kontekst, koncept, arhitektura, savremeni dizajn

Keywords: Interior design, contex, concept, architecture, contemporary architecture

\section{UVOD}

\subsection{Opis izabrane teme}

Ovim istraživačkim radom kombinuju se umetnost, dizajn, graditeljsko nasleđe i savremene metode projektovanje enterijera. Time se dolazi do ideje očuvanja objekta i estetskog ulepšavanja. Dizajnom enterijera predviđeno je očuvanje postojećih kvaliteta. Sa obzirom da se objekat nalazi u jako lošem konstruktivnom ali i estetskom stanju, cilj ovog rada je da omogući stanovnicima bolje uslove za život. Neizostavni cilj svakog savremenog objekta višeporodičnog stanovanja je da se obezbedi zdrav životni prostor sa svim ispunjenim uslovima za kvalitetan život u savremenom kontekstu, podižući standarde iznad potreba osnovne egzistencije. Takvim ciljem obezbeđuje se zdravlje i blagostanje svakoj porodici.

\footnotetext{
NAPOMENA:

Ovaj rad proistekao je iz master rada čiji mentor je bio Radomir Kojić, docent spoljne umetnosti.
}

\subsection{Pojam „,madridska korala"}

„Korala“ je vrsta građevine karakteristična za stari Madrid, oblikovana kao hodnik kuća sa opštim drvenim okvirom, čiji balkoni gledaju na unutrašnje dvorište. Prvi model naseljenog i tradicionalnog susedskog zdanja je iz 17., 18. i 19. veka. Drugi Primeri se mogu naći i u drugim španskim gradovima, poput Kadiza, Malaga, Sevilje, Valensije, Valjadolid, Santander, i na raznim lokacijama u Kastilja i Leon i Kastilja La Manša. Tređi primer istih su u Južnoj Americi.

Kuće su tamne, slabo provetrene i malene - po zakonu ne mogu premašiti 30 kvadratnih metara. Raspodeljeni su u okviru rigoroznog preferencijalnog poretka koji je uspostavio jasne razlike u društvenoj klasi.

U predindustrijskom Madridu iz 19. veka, ova imanja su omogućavala smeštaj mnogim porodicama koje su stigle u glavni grad u potrazi za poslom. Dakle, većina korala nalazi se u susedstvu u blizini starih proizvodnih područja španske prestonice, kao što su susedstva Lavapies, Embajadores i La Latina.

\subsection{Cilj}

Ovaj rad ima za cilj da enterijernim uređenjem doprinese očuvanju graditeljskog nasleđa njegovim kompleksnijim uključivanjem u život savremenog čoveka.

Analizama postojećeg stanja, kombinovanjem različitih programa i tipologija komercijalnih prostora, dolazi se do rešenja koje formiraju prostor $u$ jednu celinu, dobija se jedinstveno, autentično iskustvo prostora. Ovaj rad predstavlja teorijski okvir koji daje bolji pregled i objašnjenje ovog tipa zgrade - ,madridska korala”.

\section{ANALIZA POSTOJEĆEG STANJA}

\subsection{Opis lokacije}

Objekat koji je predmet ovog istraživanja, nalazi se u Ulici Sante Lusie 17, u Madridu, Španija. U osnovi, kao i $\mathrm{u}$ volumenu, podeljen je tako da iz ulaznog dela zgrade se ulazi u unutrašnji prostor koji je srce građevine i takođe preko tog unutrašnjeg dela je pristup tj. ulaz u stanove. U ulaznom delu su smešteni sadržaji javnog karaktera i stepenišni prostor, dok su u unutrašnjem delu smešteni atrium, javni toalet, hodnik koji vodi do ulaze u stanove. Oba dela su pokrivena dvovodnim krovom, imaju istu kotu slemena. Krovna konstrukcija je od tesane građe, u sistemu nosećih greda, stubova bez naglašenog klasičnog konstruktivnog sistema. Kota poda objekta je viša u odnosu na kotu tla za $18 \mathrm{~cm}$, što zavisi od završne obrade 
poda i sleganja tla. Prozori i vrata su ili drveni ili metalni. Objekat je tokom vremena pretrpeo niz dogradnji i izmena. U diplomskom radu objekat je bio rekonstruisan u celosti uz očuvanje svih arhitektonskih karakteristika objekta.

\subsection{Objekat na kom se vrši uređenje enterijera}

Pisanih tragova o objektu koji je premet istraživanja ovog rada - nema.

Sve informacije o objektu sam stekla na predavanjima i vežbama u univerzitetu u Alkali iz predmeta Arhitektonske konstrukcije 3.

Objekat u ulici Sante Lusie 17 je model korala koji se sastoji od: prizemlja, glavni sprat i još tri sprata. $\mathrm{Na}$ osnovu konstruktivnih karakteristika i istorijskih studija o području, zaključili smo da zgrada datira 1860 . godine. U periodu kad je nastao, njegova orginalna konstrukcija se sastojala od prizemlja, prvog i drugog sprata. Period života ove građevine pretrpeo je dve velike reforme. Prva je bila dodavanje trećeg sprata, a druga kako bi se dobilo na prostoru u potkrovlju su organizovana još dva stana. Karakteristično za ovaj tip građevine je da su stanovnici na osnovu klase u kojoj su pripadali tako bili raspoređeni po spratovima.

Stanovi okrenuti prema uličnoj fasadi izlaze na male terase. Terase na spratovima iznad su bili znatno manje nego terase na prizemlju.

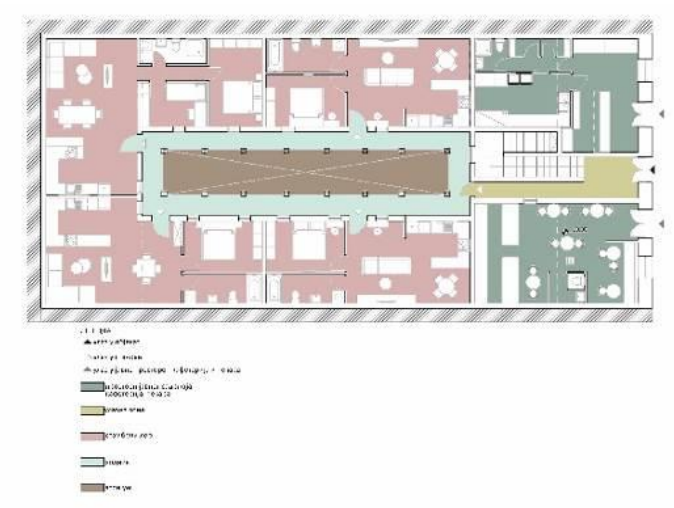

Slika br. 1 - Šema podele funkcija u prostoru

Ulazni deo građevine vodi prema atriumu (zajednički prostor) i u ulaz u stanove koje se nalaze u prizemlju i takoće nalazi se stepenišni prostor.

Objekat ima četiri izgleda, koji su određeni stranama sveta, što je posledica ortogonalne sheme ulica u pravcu istok-zapad i sever-jug. Od ta četiri izgleda, jedan gleda prema ulici a ostala tri ka komšiji su slepa.

\section{KONCEPT}

Iako je koncept dobrog dizajna veoma teško definisati u nekoliko reči, njegove osnovne vrednosti leže unutar različitih elemenata kojima je uslovljen.

Ovi kvaliteti su smešteni u prostoru, građevinama i mestima koja dobro funkcionišu, dugo traju i savršeno se adaptiraju sadašnjim i budućim korisnicima. Dobar dizajn osigurava, da izgrađeno okruženje odgovara kreativnim načina unošenja identiteta $u$ različite površine, ali $i$ jedinstvene projekte, koji se istovremeno obraćaju svojim korisnicima i funkcionalnim karakteristikama posebnih postavki.

Koncept pokušava da predstavi savremeni oblik i izgled unutrašnjeg prostora. Prostor se bavi savremenim pristupom oblikovanja enterijera tako da ne izgubi svoje osnovne vrednosti, fokusirajući se na istraživanje odnosa materijala, osvetljenja i elemenata u prostoru, kako bi na što kvalitetniji način doveo do usklađivanja prostora sa korisnikom a da $\mathrm{u}$ istom izaziva pojavu iznenađenja $\mathrm{i}$ odvlačenja od svakodnevnog života.

\subsection{Stan}

Preuređenje malih stanova može da bude popriličan izazov. Ono postaje još komplikovanije kada kombinujemo na neprimetan način stare i nove detalje i stvaramo nov ambijent $\mathrm{u}$ zatvorenom prostoru. Stan broj 1 ovog prijekta je upravo takav jedan mali stan u kom je ovom intervencijom omogućen potpuno nov izgled. Koristeći moderne načine intervencije prostora postigno je pre svega: praktičan raspored, samoodrživost, relaksirajuće okruženje, funkcionalni prostori, zdravlje, adaptibilnost, pristupačnost i bezbednost. Uz par inovacija stan sada deluje mnogo prozračnije. Prostor se sastoji od ulaznog dela koji direktno gleda na dnevni boravak, kuhinju i trpezariju. U levom delu nalazi se spavaća soba i kupatilo. Komfor ovog rešenja ogleda se u tome što je, pored činjenice da su sve funkcije porodičnog stana ispunjene, dobijen je prostran dnevni boravak koji služi i za obedovanje i za okupljanje porodice.

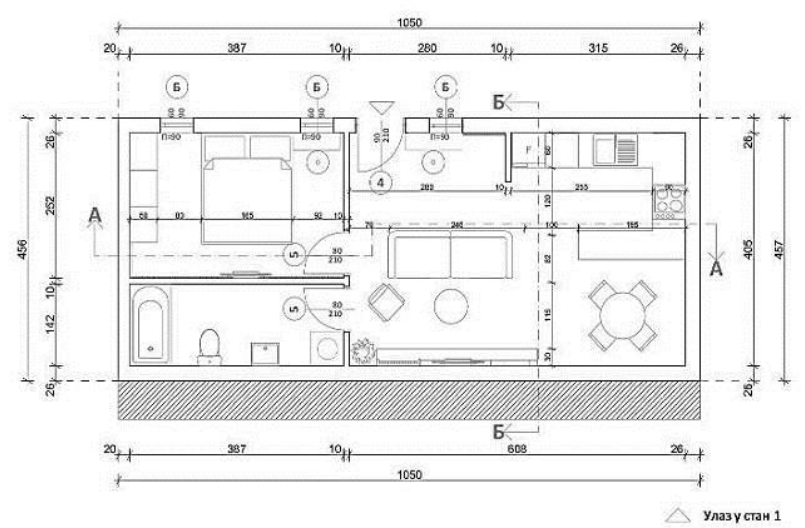

Slika br. 2 - Osnova stana

\subsection{Kafeterija}

Dizajn i arhitektura kafeterija doprinose promeni konteksta ljudi kada odu na šolju kafe sa produbljenim iskustvom, odnosno više od pukog degustiranja pića, ova osoba će osetiti da je okruženje dobrodošlo za provoditi vreme sa prijateljima, porodicom. A da bi se to postiglo, okruženje zahteva da bude prijatno gde se može razgovarati, živeti i raditi. Na taj način dizajn predtavlja strateški saveznika, privlačeći nove potrošače koji garantuju deo finansijske održivosti kompanije. Nameštaj, boje, fotografije, slike i istorija kompanije utiču na poslovanje kafeterije. Novoprojektovani prostor kafeterije ima 35 kvadratnih metara. Prostor je organizovan na sledeći način:

Uz ulaz u objekat nailazimo na šank koji se prostorire kroz prostor tako da deli svoju ulogu na prostor namenjen spremanju kafe i prostor namenjen spremanju hrane. 
Prostori za sedenje su raspoređeni tako da se može cirkulisati kroz prostor neometano. Preovladava nisko sedenje dok u delu kod prozora koji je jedinstven izvor svetlosti nalazi se lounge deo sedenja, i predstavlja komotniji oblik sedenja koji je namenjen za duži boravak. Deo priprema kafe i hrane treba da predstavlja pristupačnu i fleksibilnu zonu kojoj ljudi mogu posmatrati, istražiti i pristupiti. U delu sa šankom nalaze se i staklene prodajne vitrine sa laganom vrstom hrane i desertima.

U cilju stvaranja što kvalitetnijeg prostora u tako malom prostoru ideja je bila postići relaksirajuće okruženje gde će ludi da se oslobode stresa, i pospešiti oporavak prilikom mentalnog zamora. Ove karakteristike i atributi dobro osmišljenog unutrašnjeg okruženja, privlače svoje korisnike i u potpunosti ih podržavaju na putu ispunjenja njihovih želja.

Takođe ergonomija prostora podrazumeva omogućavanje dizajniranja okruženja koja će savršeno pristajati ljudskoj formi. Pravilan ergonomični dizajn uzima u obzir sve ljudske faktore i tom prilikom osigurava da se okruženje pravilno prilagođava zahtevima svojih korisnika.

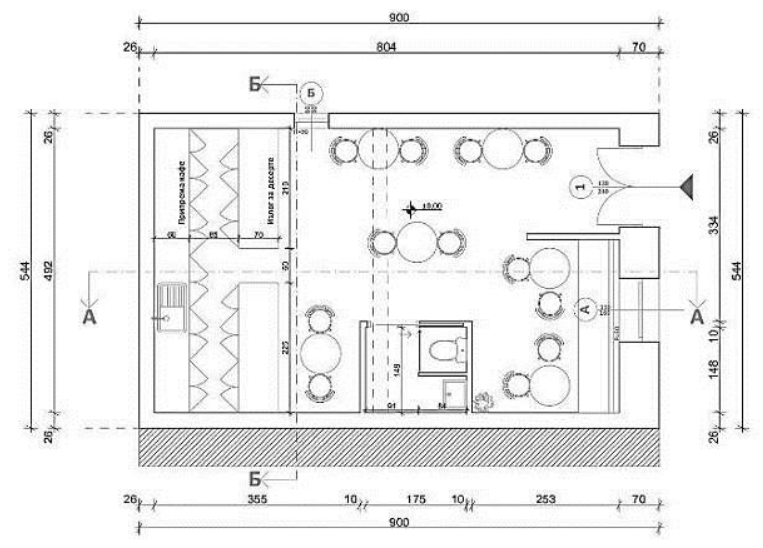

$\Delta$ Улазу кафетериіу

Slika br. 3 - Osnova prostora kafeterije

\subsection{Pekara}

Glavni prodajni prostor pekare čini središnji deo objekta gde se nalaze drvene vitrine za izlaganje peciva. Vitrine za izlaganje su izrađene od vetrikalne čelične cevi, horizontalno su povezivani držačima i dela za sklad peciva. Svaka od ovih jedinica je sama za sebe, tako da se mogu ponašati kao modularni elementi gde kada se sklope u jedan red dobija se čitav izlog.

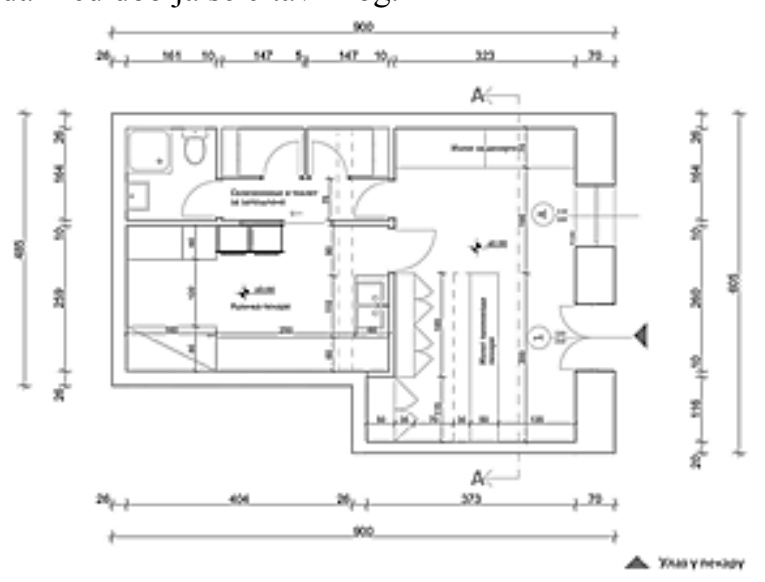

Slika br. 4 - Osnova prostora pekare
U desnom delu nalaze se frižideri gde se izlažu torte, slatkiši i još poslastica koje su proizvod rada pekare. Raspored prostorija u krugu pekare je takav da je čisti deo kruga pekare koncentrisan na jednoj strani prema glavnom ulazu pekarskih proizvoda $\mathrm{i}$ je odvojen od nečistog dela kruga pekare.

U proizvodnom procesu raspored prostorija je takav da ne dolazi do ukrštanja puteva iz pripremnog dela procesa proizvodnje sa putevima kojima se transportuju pekarski proizvodi. Veličina pekare iako je mala omogučava nesmetan rad ljudi i nesmetan pristup uređajima $\mathrm{u}$ toku rada i održavanja.

\subsection{Materijali}

Sklop materijala u objektu je kombinovan tako da poštuje postojeće materijale i da uklopi nove materijali koje će dati potpuni mir ali i novi čar objektu. Moderna, kontrasna i osvežavajuća atmosfera doprinosi korisnicima blagostanje. Dizajn koji u svom centru pažnje ima zdravlje može doprineti mentalnom i fizičkom blagostanju i optimizovati iskustva ljudi koji se nalaze u izgrađenim jednicama.

Čitav prostor je topao i pod čitavog enterijera je izrađen od drveta, osim u prostor pekare, gde je betonski pod, dok su zidovi i plafon kombinovani u belu boju. Pored toga se kroz prostor pojavljuju elementi od metala i hroma, kao što su zidni paneli u različitim oblicima i kolorita. Za radne površine se koriste uglavnom alu presvlake, teraco kamen i mermerne ploče.

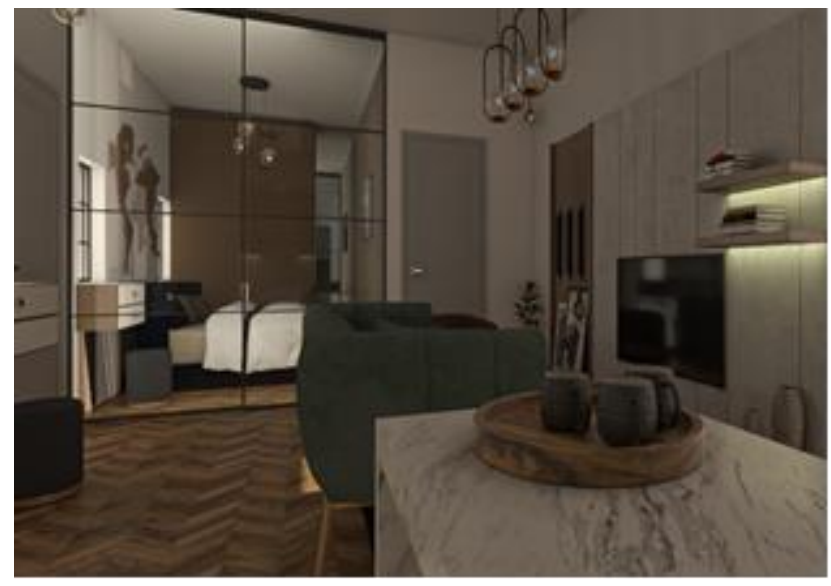

Slika br. 5 - 3d prikaz dnevnog boravka

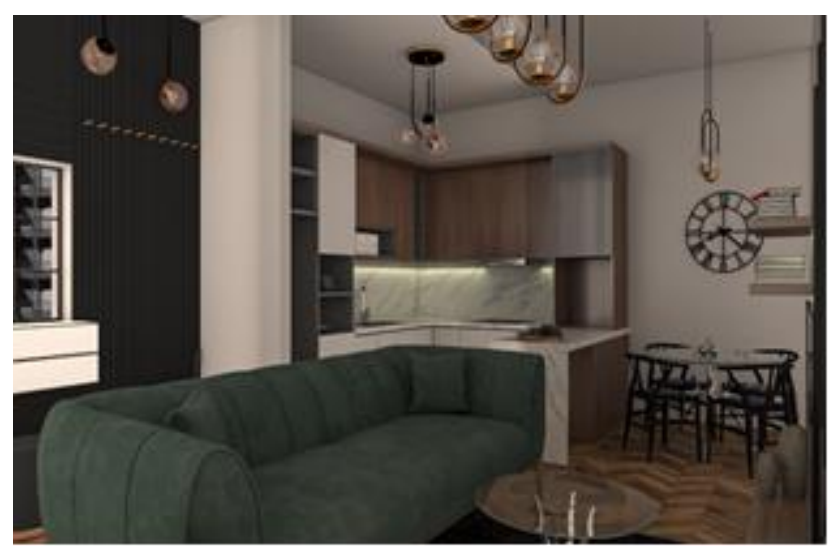

Slika br. 6 - 3d prikaz dnevnog boravka 


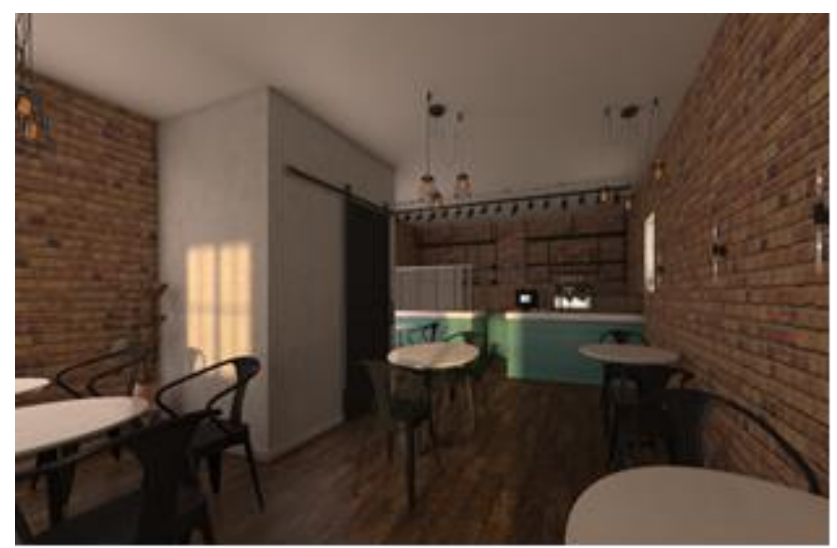

Slika br. 7 - 3d prikaz kafeterije

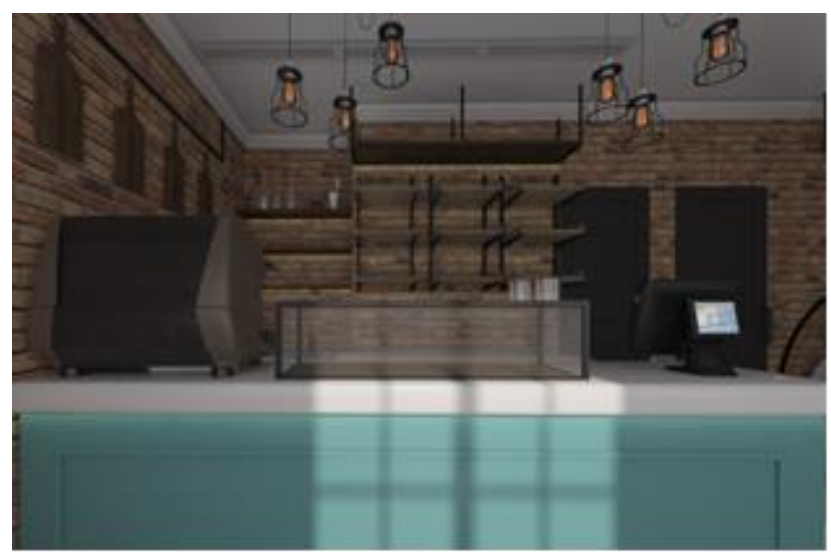

Slika br. 8 - 3d prikaz pekare

\section{ZAKLJUČAK}

Inovacije u arhitekturi su bez sumnje izuzetno važne, ali očuvanje i obnavljanje starih zgrada je takođe važno jer su ti stari spomenici odraz naše istorije, pomažu nam da razumemo i poštujemo ljude koji su živeli u različitim periodima sa različitim navikama i tradicijama. Stavke koje su prethodno razmatrane, uključujući istorijske i sociološke kontekste koji su doveli pre svega, do otvaranja i korišćenja napuštenih prostora, a potom i do toga da se u njima stvaraju različiti sadržaji.

Ugledajući se na primere studije slučaja, gde se preliću motivi kao što su upotreba materijala i prostorna organizacija, proistekao je koncept i program ovog prostornog rešenja.
Koristeći kvalitet već postojećeg unutrašnjeg prostora, uz određene intervencije, stvorena je fluidna, logična i jasna povezanost među različitim funkcionalnim celinama. Pored materijalizacije i rasvete, koje imaju veliku ulogu u formiranju željene atmosfere, ubacivanjem funkcionalnog i estetski složnog nameštaja, uz obavezno poštovanje konteksta i postojećih vrednosti prostora, enterijeru je dat specifični izgled u odnosu na bilo koji prostor slične ili identične namene.

\section{LITERATURA I REFERENCE}

[1] Petrović M., Keković A.: „Savremeni principi intervencija na spoljašnjim i unutrašnjim delovima spomenika graditeljskog nasleđa“. Zbornik Građevinsko-arhitektonskog fakulteta 2010, str. 125155

[2] Petermans, A. (2013). Dizajn za iskustvo u modnoj industriji: strategije suočavanja u doba homogenizacije. Univerzitet Hasselt. Arhitektonskoumetnički fakultet. Belgija.

[3] Jaime Santa Cruz Astorqui's : doktorske teze : Istraživanje pri politehničkom univerzitetu u Madridu na temu : ESTUDIO TIPOLÓGICO, CONSTRUCTIVO Y ESTRUCTURAL DE LAS CASAS DE CORREDOR EN MADRID, Madrid 2012, str.77 - 102

\section{Kratka biografija:}

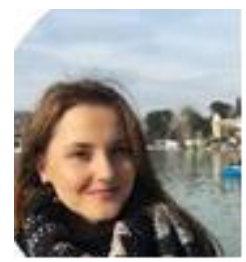

Irena Čičonovska rođena je u Bitolju, R. Makedonija 1995. God. Osnovne studije na Fakultetu tehničkih nauka iz oblasti Arhitektura završila je 2019. Godine. Iz oblasti graditeljskog nasleđa. Master rad brani 2021. Godine u oblasti Dizajna enterijera, primenjenog na graditelsjko nasleđe. 